the other hand there seems to be very little unemployment among the professional classes. The very extensive sackings and cut-backs in all government departments as well as in private industry have reduced employment, but amongst professionals there seems to have been enough mobility and opportunity for them to move overseas.
The ex-Dean of the Engineering School was reported as saying that of 11,000 Chilean engineers, 4,000 are now in Venezuela.

The Chilean Physical Society (SOCHIFI), under its president Claudio Gonzalez, continues to function and hold its scientific meetings in the usual way, although with considerable difficulty because of the loss of members and reduced financial support. One of its present preoccupations is that, since all elections are prohibited in Chile, it is unable (like many other organisations) to replace those committee members who leave the country or retire. It may shortly find itself with no committee at all.

\section{Overheads: a growing problem}

Colin Norman reports from Washington on a growing dispute involving overhead costs associated with governmentfunded academic research

THE federal government in the United States will spend about $\$ 3,000$ million this year to support research and development in colleges and universities. According to one widely accepted estimate, however, between $\$ 600$ and $\$ 700$ million of those funds will be taken up by overhead costs such as heating and lighting, university libraries, departmental administration and so on.

The size of those costs has long been a source of irritation between researchers and university officials, and between the universities and the federal government, but there are signs that the irritation may develop into a serious dispute when the budgets of some research agencies are considered by Congress later this year. Moreover, the universities have been expressing considerable concern about a review of overhead costs which has been under way in the Executive branch for the past 18 months. Important principles underlying the support of research in the United States are involved, and university officials are now preparing for battle.

It is easy to see why concern about overhead costs is growing. Overheadswhich are usually referred to as indirect costs-have been rising faster than the direct costs of doing research in the past few years, which means that indirect costs have been taking up a steadily increasing share of the federal support for academic research. Since, until very recently, total federal funds for basic research have been declining in purchasing power, university scientists are alarmed that the universities are taking an increasingly large bite out of already scarce resources.

And there seems to be a feeling among conservatives on Capitol Hill that the universities may be using federal research grants as a way to obtain revenue to support a variety of questionable activities. A staff aide to one right-wing Congressman argued in an interview last week, for example, that "the taxpayer is getting ripped off because the universities are turning basic research into a porkbarrel" for higher education. Indirect costs, he opined, are "a giant subsidy to the universities".

Such sentiments naturally touch a raw nerve among university administrators who are already grappling with steeply rising costs and diminishing federal support. They generally argue, however, that much of the criticism is based on a misunderstanding of the nature of indirect costs and the manner in which they are calculated. Though a number of extremely complex accounting procedure are involved, the basic concept is relatively simple. Procedures differ from one institution to another, but it generally works as follows.

When a researcher applies for a grant for a particular project, he calculates the direct costs of salaries, equipment, technicians' time, computer use and so on. The university then adds a fixed percentage for overheads, and the application is submitted to the federal government. If the grant is awarded, the university keeps the overheads and passes the funds for direct costs to the researcher.

The indirect costs are supposed to cover items and services which are shared by a number of research projects and which cannot be charged to any individual grant. Each university calculates its own indirect cost rate each year, but it is allowed to include only certain items specified by the federal government in a document known as FMC 73-8. The rate charged by the university is subject to audit to ensure that no unallowed costs are included. The rates differ from university to university, with the private univarsities generally charging the highest overheads and the large state universities, which receive some state subsidies and where economies of scale apply, charging lower rates. At Stanford, for example, the rate is $58 \%$, which means that for every $\$ 100$ required for the direct costs of a research project, the university adds $\$ 58$ to the grant application to cover overheads.

A good deal of confusion has arisen because different universities express their indirect cost rates in different ways, with some expressing it as a percentage of researchers' salaries and others as a percentage of total direct costs, but there is one inescapable fact: however they are expressed, indirect cost rates are increasing sharply. According to a Congressional staff investigation published last year, for example, the average overhead cost rate has increased from about $30 \%$ in 1970 to about $35 \%$ in 1975 . At Stanford, the rate has gone from $47 \%$ to $58 \%$ in the past six years.

The universities can cite good reasons for the increases. Charles V. Kidd, executive secretary of the Association of American Universities, notes, for example, that a number of recent federal regulations, such as equal pay requirements, privacy legislation, occupational safety and health regulations and so on, have placed considerable cost burdens on the universities, and many items, such as fuel costs, have been rising particularly steeply. According to William F. Massey, ViceProvost of Stanford, for example, the university's fuel bill alone has climbed from $\$ 800,000$ to $\$ 5.5$ million in four years. Moreover, Kidd argues that because of the general financial squeeze on the universities in the past few years, institutions have been more diligent in claiming their legitimate costs from the government, and that has tended to push the cost rates up.

Nevertheless, in response to concerns over rising indirect costs, the Department of Health, Education and Welfare (HEW), which is the largest federal sponsor of academic research, has been reviewing the ground rules governing indirect cost rates. In July 1975, HEW proposed a number of revisions to FMC 73-8 which would have placed severe restrictions on the types of services which the universities could claim as indirect costs. Under the HEW proposal, for example, the universities would no longer have been able to include the costs of libraries in their in- 
direct cost calculations, and some administrative expenses would also have been excluded.

The universities complained bitterly, and last month HEW revised the proposals to make them a little more palatable. The proposed revisions are now under consideration in the Office of Management and Budget, and it will be several months before any formal changes, if any, are made to FMC 73-8. If any revisions are made, they will inevitably restrict the amounts which can be claimed by the universities.

There are indications, however, that some stiff criticisms of indirect research costs may break out on Capitol Hill this year. Some of the Congressmen and Senators who in the past few years have poured scorn on research projects with trivial-sounding titles and who have criticised the National Science Foundation (NSF) for its grant review procedures, are beginning to take a critical look at the increasing indirect cost rates. Thus, for example, Robert
Michel, a Republican from Illinois who was instrumental last year in blocking funds for a behavioural science project which he found distasteful, questioned the rapid escalation of indirect costs in NSF grants when the agency's budget was before Congress last year. He indicated that he would take a closer look at the matter this year. And George Archibald, a key staff assistant to former Representative John Conlan, NSF's chief critic in recent years, is now administrative assistant for Conlan's successor and has already begun to investigate the matter of research overheads for his new boss.

Some of the criticisms are likely to surface when a subcommittee of the House Committee on Science and Technology holds a public hearing on indirect costs on February 22. And the House Appropriations Committee is also expected to probe the matter when the budget for the National Institutes of Health is under consideration.

Few observers here are willing to predict the outcome of these various executive and legislative investigations, but one veteran science policy watcher, now working for the White House, notes that skirmishes over indirect costs have erupted at various times since the federal government became a major sponsor of academic research in the second World War and he speculated that this skirmish will follow the familiar pattern: there will be considerable argument, the federal ground rules will be tightened and the dispute will die away until the next skirmish arises.

This time, however, there is a potent combination of irritants arising from the steep increase in overhead rates, the serious financial situation of many universities, and a strong desire among fiscal conservatives in Congress to seek ways to cut the federal budget. The dispute goes to the heart of the system by which the federal government supports university research, and it is thus of considerable importance to the overall health of American science.

\section{Taking politics out of health}

KEEPING an earlier pledge to "depoliticise" the National Instituites of Health (NIH), Joseph A. Califano, the new Secretary of Health, Education and Welfare (HEW), last week paid a visit to the NIH campus to announce that the Canter Administration thas decided to retain Dr Donald S. Fredrickson as NIH Director. The announcement, delivered to a packed audience of research workers, was included in a gentle pep talk in which Califano again promised to insulate NIH from partisan politics, and gave assurances that he would personally seek more resources for biomedical research.

The announcement, and the fact that Califano went to NIH to deliver it, should help to soothe complaints from biomedical researchers that NIH has been subjected to unwelcome political pressure in recent years. During the Nixon Administration, for example, candidates for NIH advisory committees were screened for their political affiliations, and two NIH directors have recently been fired, reportedly for political reasons. The first, Dr Robert Q. Marston, was dismissed by $\mathrm{Mr}$ Nixon in January 1973 for opposing budget cuts and the elimination of some cherished training programmes, and his successor, Dr Robent $\mathrm{S}$. Stone, was fired by $\mathrm{Mr}$ Ford in January 1957 for alleged administrative incompetence.

Dr Fredrickson, a well respected scientist and administrator, made known his desire to stay on as NIH
Director, but there was widespread speculation over whether the Carter Administration would retain him or replace him with a political appointee. In announcing the decision to keep Frednickson as Director of $\mathrm{NIH}$, Califano said that the Administration had looked "only for excellence" and he had not asked any candidate for a post in HEW about his or her political views. Frederickson, he said, had been selected because he is "the best person to do the job that has to be done".

Although Califano's remarks went down well with his audience, he himself acknowledged that the problems which have been afflicting NIH in recent years cannot be cured simply by ending the political screening of candidates for NIH posts. NIH has been suffering from a combination of budgetary stringencies and rapidily shifting priorities as funds have been channelled into cancer research and, to a lesser extent, heart research at the expense of some o.ther programmes. To a large extent, those shifts in priorities have resulted from legislation which has given the National Cancer Institute a privileged political status in NIH. And there has also been a trend which has resulted in a growing proportion of NIH funds being disbursed as contracts rather than grants-a trend which has increased the central management of biomedical research, but which thas met with stiff resistance from academic scientists.
In response to some of the concerns which have been expressed in the past few years about the growing politicisation of NIH and the disparities in funding, Congress established a Presidential commission under the chairmanship of a former medical school dean, Franklin Murphy. The Murphy panel last year issued a number of recommendations designed to reduce the privileged status of the cancer institute and to ease the strains within NIH. The Ford Administration made no move to implement the proposals, however, and the question now is whether or not Califano will act on them.

As for funds for NIH, although they have been increasing in the past few years, they haven't kept pace with inflation. According to an analysis recently completed by NIH's budget office, for example, the proportion of research grants approved by peer-review committees which have actually been funded has declined from $58 \%$ to $35 \%$ over the past three years, and it will drop to $32 \%$ next year if Mr Ford's final budget proposals are implemented. Califano said, however, that "I believe the work you do here, and that basic research generally in health, is critical for our society and needs additional support and resources, and l'il do my best to try and get them for you".

That went down particularly well with his listeners.

Colin Norman 